\title{
Litofácies glaciomarinhas na Formação Jequitaí: possíveis implicações na redistribuição de diamantes a oeste da Serra do Espinhaço (MG)
}

\author{
Mario Luiz de Sá Carneiro Chaves ${ }^{1}$,José Torres Guimarães ${ }^{2} \&$ Kerley Wanderson Andrade ${ }^{3}$
}

\begin{abstract}
Resumo A Formação Jequitaí, de idade neoproterozóica, ocorre em discordância erosiva sobre o Supergrupo Espinhaço (Paleo-Mesoproterozóico), com larga distribuição entre a cidade homônima e a borda oeste da Serra do Espinhaço. Essas sequências são cobertas por depósitos cretácicos da Formação Abaeté. Na atualidade, uma origem glaciogênica para a Formação Jequitaí é consensualmente admitida, com a caracterização de diferentes litofácies na unidade, entretanto sem envolverem uma relação com os depósitos diamantíferos cenozóicos que em certos locais ocorrem espacialmente associados à sequência. A discussão apresentada, que envolve as litofácies glaciais e seus possíveis relacionamentos com os sedimentos mineralizados, baseou-se no mapeamento geológico das folhas Jequitaí e Bocaiuva (1:100.000), possibilitando também que fossem integrados estudos com diferentes objetivos originais. Reconheceram-se sete litofácies glaciomarinhas (L1 a L7) na sequência, constituídas de metadiamictitos ou quartzo-metarenitos, seis delas reunidas em uma associação de litofácies, as quais representam depósitos de degelo de base de geleira, de leque aluvial marginal de geleira, de deltas proglaciais de contato de geleira e de degelo de icebergs. Constatou-se que regionalmente os depósitos diamantíferos associam-se de modo preferencial aos sedimentos cenozóicos encontrados no contexto de metadiamictitos maciços basais, pertencentes à Litofácies L1. No entanto, deve-se ressaltar a presença de conglomerados do Cretáceo Inferior (Formação Abaeté) como também possíveis espalhadores dos diamantes, pelo menos localmente. Essa multiplicidade de depósitos fonte secundários pode ser o fator determinante para uma distribuição aparentemente aleatória da mineralização, e o principal responsável pela quase incontrolabilidade prospectiva da mesma.
\end{abstract}

Palavras-chave: Formação Jequitaí, litofácies glaciomarinhas, Serra do Espinhaço.

\begin{abstract}
Glaciomarine lithofacies in the Jequitai Formation: possible implications for the redistribution of diamonds to the west of the Espinhaço Range $(M G)$. The neoproterozoic Jequitai Formation, occurs as erosive discordance on the Espinhaço Supergroup (Paleo-Mesoproterozoic), presenting a large spatial distribution between the Jequitai town and the western margin of the Espinhaço Mountain Range. These sequences are covered by cretaceous rocks of the Abaeté Formation. Actually, a glacial origin for the Jequitaí Formation has been widely accepted, with several studies focused the characterization of different lithofacies in this unit. However, such studies do not involve a relationship with the problematic question of Cenozoic diamond-bearing deposits that occur in the proximities of the glacigenic sequence. The paper presents a discussion related to the probable relationship between the glacigenic lithofacies and the diamondiferous gravels, based on the geologic mapping of the Jequitai and Bocaiuva quadrangles (1:100,000 scale), which also allowed the integration of previous studies with different original objectives. Seven glacimarine lithofacies with metadiamictite and quartz-metarenite rocks (L1 to L7) have been recognized, six of them grouped in a lithofacies association. These lithofacies represent thaw deposits stemming from glacier, alluvial fan in glacier margin, proglacial deltas of glacier contact, and thaw of icebergs. It was also observed that the diamondiferous deposits are associated with Cenozoic sediments that are regionally found in the context of massive basal metadiamictites belonging to L1 Lithofacies. On the other hand, it should be noted the presence of Lower Cretaceous conglomerates (Abaeté Formation) as well as the possible scattering of the diamonds, at least locally. The multiple varieties of deposits from secondary source can be the determining reason for a seemingly random distribution of the mineralization, and the main responsible for an almost uncontrollable prospective aspect them.
\end{abstract}

Keywords: Jequitaí Formatiom, glacimarine lithofacies, Espinhaço Range.

INTRODUÇÃO Desde o final do século XIX são conhecidos sedimentos aluvionares diamantíferos, cenozóicos, na região do médio Rio São Francisco (Mi- nas Gerais), em especial nos arredores da cidade de Jequitaí. Em alguns locais esses depósitos situam-se em sobreposição ou nas cercanias imediatas de metassedi-

1 - Universidade Federal de Minas Gerais, Instituto de Geociências, Centro de Pesquisa Prof. Manoel Teixeira da Costa, Campus da Pampulha, Belo Horizonte (MG), Brasil; e pesquisador CNPq. E-mail: mchaves@ufmg.br

2 - Companhia de Pesquisa de Recursos Minerais - Superintendência Regional de Salvador, Salvador (BA), Brasil.

E-mail: torres@sa.cprm.gov.br

3 - Programa de Pós-Graduação em Geologia do IGC-UFMG e GEOMIL Ltda, Belo Horizonte (MG), Brasil. E-mail: kerley@geomil.com.br 
mentos neoproterozóicos, caracterizados como de natureza glaciogênica no início do século XX, e atualmente inseridos na Formação Jequitaí. No trabalho, serão discutidas as duas linhas de hipóteses que tem procurado explicar a origem dos diamantes em tais depósitos. A primeira relaciona a citada proximidade das unidades glaciogênicas com os sedimentos colúvio-aluvionares contendo diamantes, presumindo a origem da mineralização nos glaciolitos. No outro modelo, demonstra-se que as rochas glaciais não podem ser regionalmente as fontes exclusivas dos diamantes, sugerindo que esses foram redistribuídos pelos conglomerados eocretácicos da Formação Abaeté (Grupo Areado), que afloram reliquiarmente na região.

Integrando o Programa Geologia do Brasil Levantamentos Geológicos Básicos (Convênio CPRM/ UFMG-IGC-CPMTC), as folhas Jequitaí (SE.23-XC-II) e Bocaiuva (SE.23-X-C-III) foram mapeadas na escala 1:100.000 pelo primeiro autor e equipe (Chaves \& Benitez 2006, Chaves \& Andrade 2009). Um dos objetivos desses trabalhos foi o levantamento, descrição e detalhamento dos depósitos diamantíferos, levando também a discussões quanto à fonte do mineral. No presente estudo, os modelos previamente propostos foram revisados, tendo por base dois enfoques principais: a reavaliação dos depósitos da Formação Jequitaí do ponto de vista do reconhecimento e distribuição espacial de suas litofácies e a interpretação de seus ambientes de sedimentação. Além disso, utilizando-se do acervo préexistente e os dados recém obtidos nos mapeamentos das folhas citadas, enfatizou-se a possível relação dos diamantes com os glaciolitos.

LOCALIZAÇÃO E SÍNTESE GEOLÓGICA REGIONAL A região estudada localiza-se na porção centro-norte do Estado de Minas Gerais, entre o Rio São Francisco e a Serra do Espinhaço, abrangendo, de oeste para leste: (a) as pequenas serras, contínuas, da Água Fria e das Porteiras, (b) o entorno norte da Serra do Cabral, (c) a ponta norte de fechamento da estrutura anticlinória da Serra do Espinhaço Meridional, e (d) a borda oeste da Serra do Espinhaço Central. Tais áreas serranas arrasadas representam estruturas anticlinoriais, constituídas em seus núcleos por unidades do Supergrupo Espinhaço, margeados por metassedimentos de unidades mais recentes (Fig. 1). Dentre os principais mapeamentos geológicos, em diversas escalas e/ou com diferentes objetivos que abrangeram tal área, citam-se os trabalhos em escala regional de Menezes Filho et al. (1977) e Souza (1985), e os de semidetalhe (1:100.000 ou maiores) de Paiva Filho \& Ponçano (1972), Viveiros \& Walde (1976), Penha (2001), Silva \& Magalhães (2005), Martins (2006), Chaves \& Benitez (2006) e Chaves \& Andrade (2009).

Em termos geotectônicos, tal região está situada na zona de transição entre o Cráton do São Francisco e a margem oeste da Faixa de Dobramentos Araçuaí, ocorrendo unidades paleo e mesoproterozóicas do Supergrupo Espinhaço (grupos Diamantina e Conselheiro Mata), unidades neoproterozóicas do Supergrupo São Francisco (grupos Macaúbas e Bambuí) e depósitos eocretácicos do Grupo Areado (Formação Abaeté), além de coberturas cenozóicas detrítico-lateríticas e aluviais (Chaves \& Benitez 2006, Chaves \& Andrade 2009). A sedimentação do Supergrupo Espinhaço iniciou-se por volta de 1,7 Ga (Machado et al. 1989, Dussin 1994) e, segundo MartinsNeto (1998), essa megassequência foi depositada em uma bacia intracratônica do tipo rifte-sag. As sequências superiores, Macaúbas e Bambuí, foram acumuladas respectivamente em bacias do tipo rifte/margem passiva e foreland (Chang et al. 1988, Martins-Neto et al. 1997), enquanto a Formação Abaeté, constitui a base mesozóica da Bacia Sanfranciscana (Sgarbi 2000).
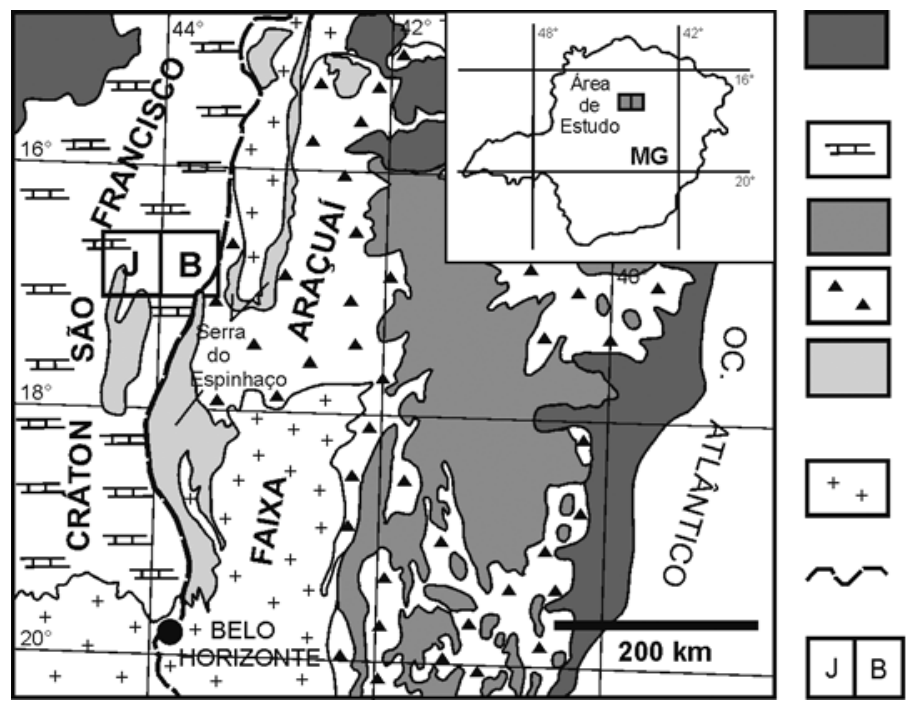

Coberturas Fanerozóicas PROTEROZÓICO

Coberturas Cratônicas

Magmatismo pré- a pós-Colisional

Sequências Metassedimentares (indivisas) do Orógeno Araçuaí

Supergrupo Espinhaço

ARQUEANO

Embasamento Pré-Transamazônico

Limite entre Cráton do São Francisca e a Faixa de Dobramentos Araçuaí

Folhas Jequitaí (J) e Bocaiuva (B)

Figura 1 - Localização das folhas geológicas 1:100.000 Jequitaí (J) e Bocaiuva (B) na região centro-norte de Minas Gerais, apresentando o arcabouço geológico regional. 
A GLACIAÇÃO JEQUITAÍ-MACAÚBAS Referências iniciais às rochas conglomeráticas da região de Jequitaí devem-se a Derby $(1878,1879)$, para as quais Branner (1919) sugeriu uma origem glacial. Moraes \& Guimarães (1930) e Moraes (1932) batizaram tal unidade como "Formação Macahubas" no vale do Rio Jequitinhonha, depois elevada ao status de grupo e comportando ainda diversas subdivisões (eg., Hettich 1977, Karfunkel \& Karfunkel 1976, Noce et al. 1997). Entretanto, a designação Formação Jequitaí para essas rochas foi cunhada por Oliveira \& Leonardos (1943), em alusão ao seu locus tipicus de reconhecimento. Isotta et al. (1969) descreveram as estrias deixadas pelo arraste de geleiras no substrato rochoso (Supergrupo Espinhaço), diretamente cobertas pela Formação Jequitaí, tornando inquestionável sua origem glacial. A partir daí, acrescentaram-se dezenas de estudos aos existentes, e agora a unidade (isoladamente) é considerada de cobertura cratônica, tendo como equivalente lateral a Formação Serra do Catuni, integrante do Grupo Macaúbas na Faixa Araçuaí (eg., Noce et al. 1997, Pedrosa-Soares et al. 2000, Uhlein et al. 2004, 2007).

No entanto, ainda persistem diversas controvérsias quanto ao modelo integral de sedimentação da Formação Jequitaí. A partir das pesquisas de Isotta et al. (1969), outras progressivamente levaram à proposição de um esquema regional onde, a oeste, estariam presentes fácies glaciocontinentais (região de Jequitaí), que passariam de modo gradual em direção a leste para fácies transicionais e glaciomarinhas, segundo uma hipótese de glaciação de dimensões continentais (eg., Pflug \& Schöll 1975, Karfunkel \& Karfunkel 1976, Hettich 1977, Dardenne et al. 1978, Karfunkel \& Hoppe 1988). As marcas do arraste de geleiras esculpidas na sequência inferior, o aspecto maciço comum das rochas nos principais sítios minerados e uma aparente inexistência de estruturas sedimentares primárias, além da presença interna na sequência de possíveis eskers e varvitos, serviram de base para tal modelo, classificando então essas rochas em Jequitaí como tilitos.

Em proposta antagônica, Hercos \& Martins-Neto (1997), Martins-Neto et al. (1997, 1999) e Martins-Neto \& Hercos (2002) reconheceram a posível existência de estruturas primárias relacionadas a fácies de sistemas fluviais entrelaçados pró-glaciais (outwash plains), o que, juntamente com observações adicionais, levaram à reinterpretação das geleiras como do tipo de altitude. Nesses estudos, foi defendido o modelo de glaciação alpina baseando-se em uma sugerida geometria em forma de vale da sequência, na discordância erosiva na base dos depósitos glaciogênicos, e nos dados de paleocorrentes que mostraram diferentes direções de transporte em arenitos interpretados como outwash. A topografia necessária para este tipo de glaciação teria sido gerada pelo soerguimento das ombreiras do rifte neoproterozóico, na fase inicial de desenvolvimento da Bacia Macaúbas.

Novos estudos, entretanto (Cukrov 1999, Cukrov et al. 2005, Uhlein et al. 1999, 2004, 2007), argumentaram a favor de uma origem dos sedimentos glaciais em ambiente marinho raso. Esses autores se embasaram na relativa raridade de clastos com granulometria maior que seixo na base da sequência e na quase ausência de outras litofácies que poderiam representar depósitos de lavagem (outwash) ou de eskers. Em tais estudos ainda foi caracterizada a homogeneidade dos metadiamictitos em relação a sua grande espessura, o que levou a uma nova interpretação sobre a gênese dos glaciolitos, então associados ao recuo de geleiras durante uma transgressão marinha.

A distribuição da Formação Jequitaí é irregular, e seus depósitos apresentam espessuras variáveis de alguns poucos metros até mais que $200 \mathrm{~m}$ (Chaves \& Benitez 2006, Chaves \& Andrade 2009). A Formação Serra do Catuni, sua correlata, ocorre somente a leste da Folha Bocaiúva, onde tem espessura estimada em $250 \mathrm{~m}$ (Martins 2006). Ainda não existe um consenso sobre a idade de deposição dessas unidades. Datações obtidas por Pedrosa-Soares et al. (2000), restringiram sua idade superior em $950 \mathrm{Ma}$ (U/Pb SHRIMP em zircão detrítico), enquanto Babinski \& Kaufman (2003) e Babinski (2005), determinaram um período de sedimentação aproximado entre $740 \pm 22 \mathrm{Ma}(\mathrm{Pb} / \mathrm{Pb}$ em carbonatos do Grupo Bambuí na capa da sequência) e $875 \pm 9 \mathrm{Ma}(\mathrm{Pb} / \mathrm{Pb}$ em zircão detrítico da Formação Bebedouro, correlata da Formação Jequitaí na Chapada Diamantina Oriental, Bahia).

\section{DESCRIÇÃO E INTERPRETAÇÃO DAS LITO-} FÁCIES DA FORMAÇÃ̃O JEQUITAÍ Na figura 2, apresenta-se a distribuição da Formação Jequitaí na folha homônima, onde suas exposições são mais extensas (Chaves \& Benitez 2006), além da tentativa de separação de diferentes associações de fácies sedimentares. No escopo do presente trabalho, optou-se por tal individualização em escala ampliada, visto que bons afloramentos são descontínuos e na maior parte das vezes na forma de lajeados, dificultando a visualização de seções verticais que possibilitassem interpretações faciológicas detalhadas. Os afloramentos mais representativos ocorrem no leito do Rio Jequitaí e imediações da cidade, e nos cortes da BR-365 a norte e sul da Serra das Porteiras (Jequitaí em direção a Montes Claros).

Descrição das litofácies Sete litofácies (L1 a L7) foram identificadas na Formação Jequitaí, as quais apresentam forte interatividade e permitem caracterizar um contexto macrodeposicional único:

(L1) Metadiamictito maciço, rico em clastos, organizado em bancos de vários metros, lobulares amalgamados e com geometria interna caótica (Fig. 3A). Essa litofácies é constituída por clastos de diâmetro e composição variados, oscilando de grânulo a matacão com até $1 \mathrm{~m}$ de diâmetro, de metarenito, quartzo, filito, granito, gnaisse, carbonato e rocha metavulcânica básica. É frequente a variação composicional dos clastos ao longo da litofácies; esse fato deve refletir fontes e cargas sedimentares distintas. Uma matriz pouco expressiva de metarenito imaturo (grauvaca, arenito lítico e arcóseo), médio a muito grosso, cinza-esverdeado a castanho-esverdeado, preenche os espaços intergrãos da rocha. A desorganiza- 


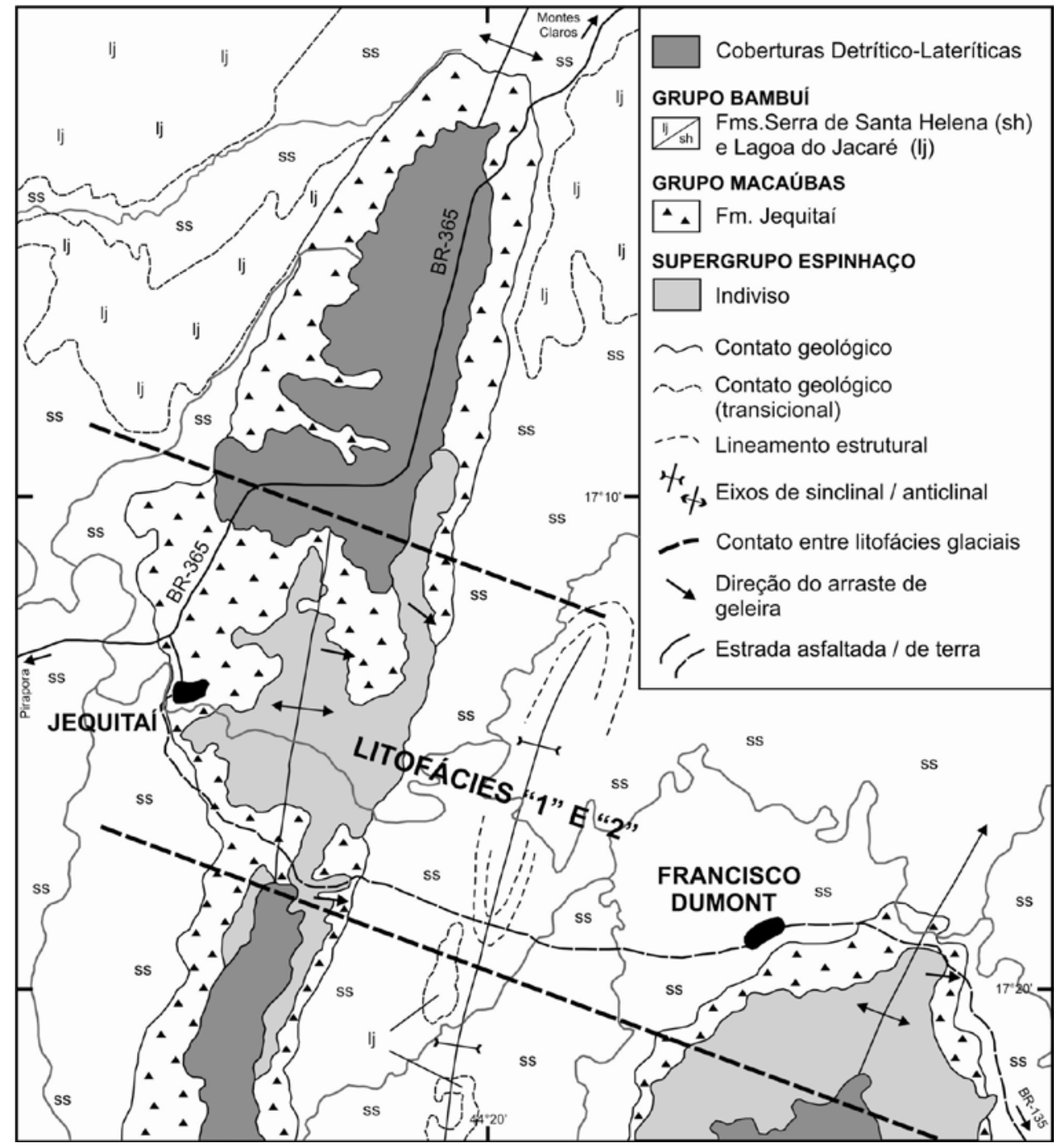

Figura 2 - Geologia local e distribuição espacial das fácies e associações de litofácies na Formação Jequitaí no âmbito da folha homônima (parcial e modificada de Chaves \& Benitez 2006, escala original 1:100.000).

ção interna desse depósito, a presença de textura polimodal mal selecionada, o arranjo de clastos que se tocam com pouca matriz e a associação com metadiamictito e metarenito impuro com estratificação sigmoidal, permitem sugerir qua a litofácies tenha sido formada por processos de fluxos gravitacionais não coesivos de sedimentos gerados em meio subaquático.

(L2) Metadiamictito maciço, rico em clastos, semelhante à Litofácies L1, porém diferindo na composição pelítica da matriz, na distribuição mais esparsa dos clastos e no menor tamanho dos mesmos. Tais características possivelmente significam distância um pouco maior da área-fonte (Fig. 3B1-B2). Vários processos interagindo num mesmo ambiente podem ter sido responsáveis pela geração dessa litofácies, mas os aspectos regionalmente identificados apontam para depósitos de degelo de icebergs.

(L3) Metadiamictito maciço, pobre em clastos, ocorrendo em bancos submétricos tabulares com grande continuidade lateral, separados por superficies de descontinuidade (Fig. 3C). Trata-se de um paraconglomera- do, cujas diferenças principais da litofácies anterior são o maior percentual de matriz, o tamanho, em média, menor dos clastos, e a sugestão de uma geometria externa sigmoidal. Interpretou-se tal litofácies, como formada a partir de fluxos de detritos coesivos e confinados.

(L4) Metadiamictito pobre em clastos, com estratificação paralela, constituído de matriz arcoseana fina, cinza-clara ou esverdeada, na qual distribuem-se clastos de composição variada e tamanho, em geral na faixa de grânulo a seixo, embora ocorram blocos e matacões isolados. Sugere-se que os processos que geraram esses depósitos foram fluxos de detritos coesivos e confinados, bem como correntes de turbidez de alta concentração (Fig. 4A).

(L5) Micrometadiamictito pobre em clastos, com estratificação cruzada acanalada de grande porte, formado por matriz de arenito impuro cinza-esverdeado e clastos (subordinados) de composição variada, semelhante à das litofácies anteriores, e tamanho médio na faixa de grânulo a seixo. Essa litofácies apresenta retrabalhamento por onda e geometria externa de ca- 

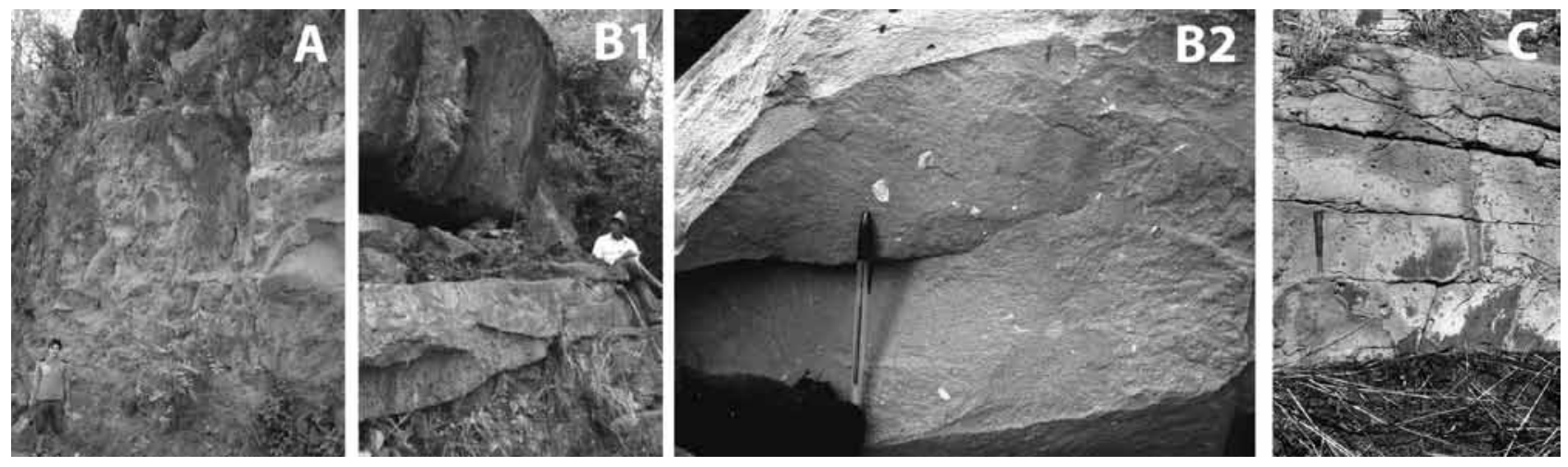

Figura 3 - (A) Aspecto geral do metadiamictito da Litofácies L1 ressaltando o seu aspecto maciço, o qual aflora extensamente nas imediações da cidade de Jequitaí; (B1) contato subhorizontal concordante da Formação Jequitai (Litofácies L2) com a Formação Córrego dos Borges na área do Morro das Bibocas (posição na Fig. 2); em (B2) detalhe do local anterior, com o metadiamictito maciço, porém com clastos de pequeno porte em matriz arenosa fina; $(C)$ aspecto principal da Litofácies L3, ressaltando a tabularidade das camadas submétricas de metadiamictitos sustentados pela matriz.
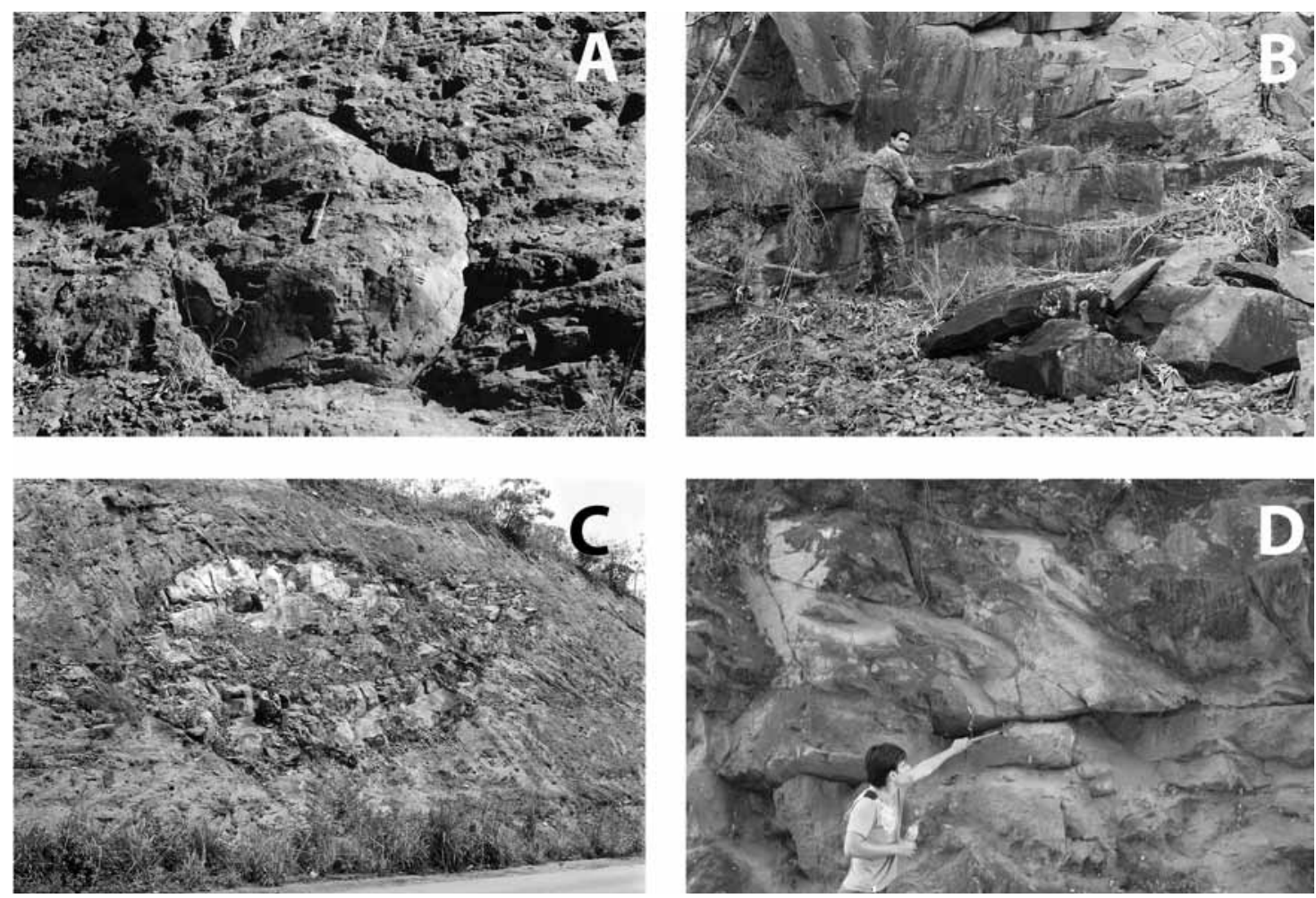

Figura 4 - (A) Clasto de quartzito com porte de matacão, na porção superior da Formação Jequitai na fácies metadiamictito pobre em clastos, com blocos e matacões isolados (Litofácies L4); (B) estruturas em forma de canal nos metadiamictitos aflorantes em corte da BR-365, da Litofácies L5, onde o colaborador aponta para o acunhamento lateral de um estrato com nítida forma de canal; $(C)$ nas proximidades do topo da seqüência, ressalta-se esta lente metarenítica intercalada em metadiamictitos da Litofácies L6, que provavelmente representa deposição em canais subaquosos sob condições ambientais glaciomarinhas; (D) quartzo-metarenito com estratificação cruzada sigmoidal da Litofácies L7 sobre os metadiamictitos maciços da base da Formação Jequitai (Litofácies L1), nos arredores da cidade.

nais amalgamados, sendo interpretada como derivada de fluxos coesivos e confinados, retrabalhados em ambiente subaquático (Fig. 4B).
(L6) Quartzo-metarenito com estratificações cruzadas acanaladas de médio porte, formando múltiplos canais amalgamados associados ao micrometadiamictito 
e ao metadiamictito estratificado e maciço. Esses depósitos provavelmente foram gerados por fluxos coesivos e confinados em ambiente subaquático (Fig. 4C).

(L7) Quartzo-metarenito impuro fino a médio, castanho e com estratificações de geometria sigmoidal, onde o sentido da paleocorrente é para noroeste. Essa litofácies foi reconhecida exclusivamente na saída da cidade de Jequitaí em direção a Francisco Dumont, logo após a ponte sobre o rio homônimo, onde capeia o metadiamictito maciço rico em clastos (L1). Interpretou-se essa litofácies como resultante da alternância de fases de deposição e erosão, com deposição acontecendo rapidamente através de processos gravitacionais de fluxos de detritos coesivos e confinados e/ou por correntes de turbidez de alta concentração, em ambiente subaquático (Fig. 4D).

A Litofácies L1 predomina na porção basal da unidade, conforme verificado em toda seção entre Jequitaí e Francisco Dumont, onde em diversos locais foi observada em sobreposição à Formação Córrego dos Borges (Supergrupo Espinhaço). Sua espessura varia de alguns poucos metros até $30-40$ m; no topo é truncada localmente pela litofácies composta por quartzometarenito rico em estratificações cruzadas sigmoidais, com 1-2 m de espessura (L7). Entretanto, em diversos locais a cobertura do bedrock é feita diretamente pela Litofácies L2, como no Morro das Bibocas ao norte de Jequitaí, apresentando cerca de $10 \mathrm{~m}$ de espessura. As litofácies L3, L4, L5 e L6 foram caracterizadas ao longo do perfil da BR-365, onde suas condições de exposição são excelentes. No trecho entre o trevo de Jequitaí até cerca de $30 \mathrm{~km}$ a norte (rumo de Montes Claros), na
Serra das Porteiras, as espessuras observadas para tais litofácies variaram entre 20 e $30 \mathrm{~m}$.

Discussão sobre as associações de litofácies e ambientes deposicionais De modo geral, a diversidade faciológica, a descontinuidade dos afloramentos e a dinâmica deposicional, não permitiram a elaboração de uma seção-tipo exata para a Formação Jequitaí na região enfocada, embora as litofácies L1 e L2 tenham sido sempre observadas na porção basal da sequência, em contato com metassedimentos do Supergrupo Espinhaço. Da mesma forma, os dados de paleocorrentes disponíveis não permitem caracterizar as direções principais dos paleofluxos presentes à época de acumulação da unidade. Entretanto, os estudos sedimentológicos e estratigráficos desenvolvidos demonstraram a existência de uma associação de litofácies subaquáticas e uma litofácies de sedimentação isolada: (i) associação de litofácies de contato de geleira (Litofácies L1, e L3 até L7); e (ii) litofácies de degelo de icebergs (Litofácies L2).

$\mathrm{O}$ estudo das interrelações de fácies em ambiente glacial, moderno ou antigo, vem tomando forte impulso nas últimas décadas, conforme discutido em detalhe por Guimarães (1996). Como, para a região em apreço, diversas interpretações de ordem genética já foram propostas, elas serão aqui discutidas e comparadas com as observações efetuadas no atual trabalho, a respeito dos relacionamentos espaciais entre as diversas litofácies presentes.

A primeira constatação verificada baseia-se nas estrias e sulcos originados pelo arraste de geleiras (Fig. 5A-B) que marcam o contato entre as formações Córrego
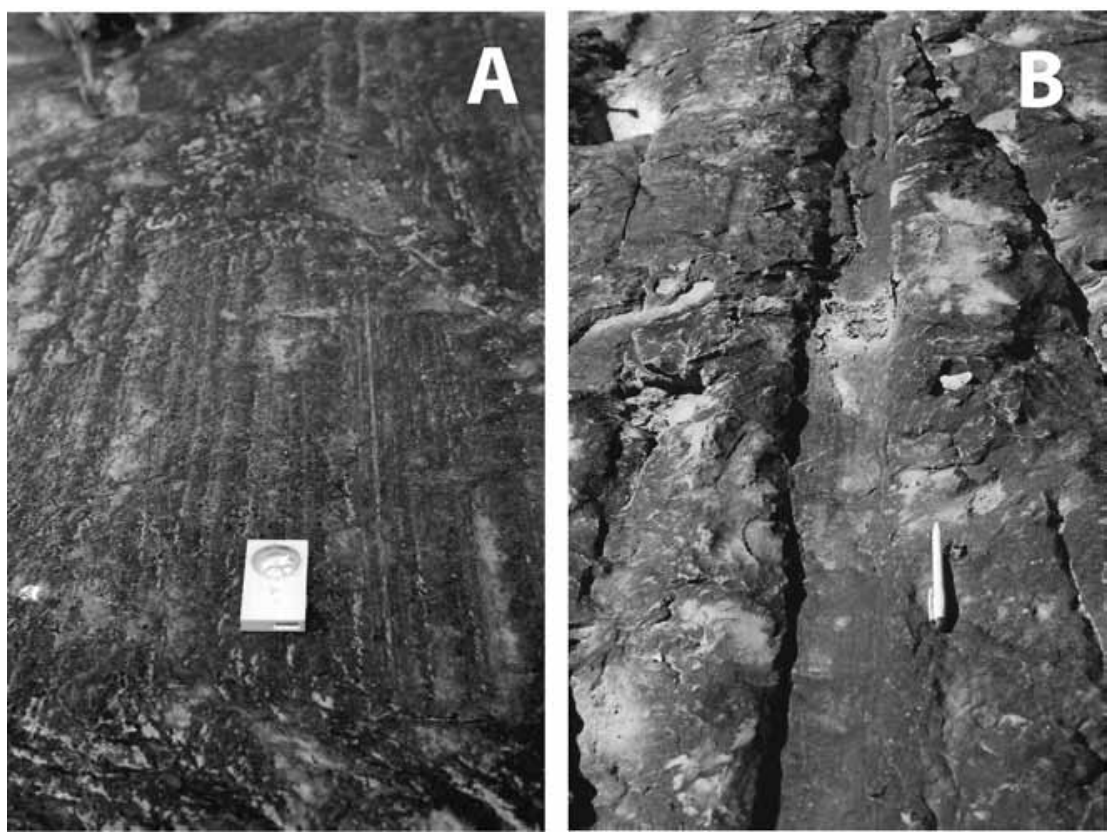

Figura 5 - (A) Limite superior da Formação Córrego dos Borges (Supergrupo Espinhaço), localmente marcado por pavimentos estriados; (B) ou mesmo sulcos profundos, originados pelo arraste de geleiras subaquáticas, conforme exemplificado na porção norte da Serra da Água Fria. 
dos Borges e Jequitaí em diversos locais. Deve ser ressaltado que além do afloramento clássico da Serra da Água Fria descrito por Isotta et al. (1969), foram descobertos outros três locais onde a mesma feição aparece nas imediações de Jequitaí e ainda na Serra do Cabral. Tratamse de estrias paralelas, de profundidade geral de até $5 \mathrm{~cm}$ com larguras entre $1-2 \mathrm{~cm}$ (Fig. 5A), podendo em alguns casos constituírem sulcos largos de até $20 \mathrm{~cm}$ (Fig. 5B). Nesses locais a direção das paleocorrentes variou sempre entre $\mathrm{N} 90^{\circ}-\mathrm{N} 120^{\circ} \mathrm{AZ}$ (Fig. 2). A uniformidade na orientação das estrias, seu paralelismo e concordância de orientações sobre grande distribuição areal, são argumentos a favor de que as geleiras agiram sobre um estrato litificado (eg., Isotta et al. 1969, Uhlein et al. 1999, 2004).

As estruturas maciças verificadas na Litofácies L1, denotam características de um depósito de despejo sedimentar de geleira, e as estratificações sigmoidais presentes na litofácies superior (arenosa fina), são típicas de lobos deltáicos. Essa última fácies, no entanto, deve ser de caráter local, e as direções de paleocorrentes observadas entre $\mathrm{N} 20-30^{\circ} \mathrm{W}$, indicam área-fonte discordante da direção geral para sudeste. Assim, em direção leste como no Morro das Bibocas e no âmbito da Serra do Cabral, os metadiamictitos mais finos, com clastos menores e distribuídos de forma esparsa, representariam porções mais distais da sequência. Possivelmente, a presença característica da Litofácies L1 nos arredores de Jequitaí, levou um grande número de autores a interpretar todos metadiamictitos da Formação Jequitaí generalizadamente como tilitos (eg., Hettich 1977, Dardenne et al. 1978, Hettich \& Karfunkel 1978, Karfunkel \& Hoppe 1988).

De outro modo, metadiamictitos ricos em clastos e metadiamictitos pobres em clastos foram inicialmente reconhecidos como litofácies distintas nos estudos de Cukrov (1999) e Cukrov et al. (2005). Esses autores consideraram tal aspecto como uma mudança vertical de fácies, onde os metadiamictitos mais pobres em clastos ocorreriam abaixo dos outros. Na visão agora apresentada as duas fácies se associam, parecendo indicar mudanças faciológicas no sentido horizontal, e os metadiamictitos pobres em clastos estariam em zonas algo mais distais na bacia. Além disso, a grande extensão superficial das litofácies L1 e L2, junto a outras características ressaltadas no item anterior, permitiram interpretá-los como glaciomarinhos. Em Jequitaí, a espessura admitida da formação varia entre $80 \mathrm{~m}$ (Cukrov 1999) e 200 m (Chaves \& Benitez 2006). Deve-se ressaltar que o mesmo ambiente já havia sido anteriormente proposto para a Formação Bebedouro, na Bahia (Guimarães 1996). Acredita-se assim que a espessura "exagerada" da unidade, bem como a comparação com sua correlata, sejam elementos que corroboram a classificação de tais depósitos como glaciomarinhos.

$\mathrm{Na}$ parte superior da associação de litofácies de contato de geleira, as abundantes estruturas de preenchimento de canais amalgamados foram consideradas por Martins-Neto et al. (1999) como fácies de um sistema fluvial entrelaçado proglacial (outwash plain). A identificação dessa fácies foi também de encontro às idéias consolidadas na literatura, de que todo o pacote da Formação Jequitaí era maciço. Entretanto, o (sub) ambiente fluvioglacial proposto para tais rochas conduziram, de modo semelhante, à interpretação de um ambiente glaciocontinental para a unidade. Esses autores, através do estudo das direções de paleocorrentes, identificaram o vetor máximo em $\mathrm{N} 18^{\circ} \mathrm{E}$, apontando a existência de um paleoalto na região da Serra da Água Fria que, sob a atuação de geleiras e ciclos sazonais de gelo e degelo, teria fornecido os sedimentos para o sistema entrelaçado desenvolvido para NNE. Assim, ainda que concordassem com os estudos prévios a favor de um ambiente glaciocontinental, tais dados levaram ao modelo de glaciação de altitude.

Algumas litofácies reconhecidas na BR-365, como metadiamictitos pobres em clastos, estratificados e com estruturas acanaladas, metaconglomerados clastosuportados de matriz pelítica, metadiamictitos ricos em clastos, estratificados, às vezes com matacões, e corpos metareníticos lenticulares inseridos, no contexto glaciomarinho proposto provavelmente representam canais subaquáticos ressedimentados, acumulados por processos gravitacionais de fluxos confinados de detritos coesivos e não coesivos, de modo análogo aos processos descritos por Guimarães (1996) na Formação Bebedouro. Esse modelo implica em duas fases de transporte durante o período glacial; a primeira para leste/sudeste, evidenciada pelas estrias de arraste de geleiras, e a segunda, onde associados uma transgressão marinha, formaram-se os canais subaquáticos ressedimentados.

Quanto à deposição dos corpos lenticulares quartzo-metareníticos destituídos de clastos, situados no topo da formação (Litofácies L6), tais feições foram interpretadas como eskers por Hettich \& Karfunkel (1978). Gravenor \& Monteiro (1983) sugeriram tratarse de "mega" matacões arrancados do substrato, hipótese que não se sustenta com a análise minuciosa do afloramento, onde foi constatada a geometria lenticular do corpo (Fig. 4C). De outro modo, aceitando-se o conceito de gênese glaciomarinha, esses depósitos podem ser interpretados como produtos de fluxos rápidos de massa transportados em túneis subaquáticos (Cukrov et al. 2005). No presente trabalho, aceitou-se tal versão, onde numa geleira de base úmida, ocorreriam lobos com seções mais finas, arenosas, dentro das partes rudíticas que contem os metadiamictitos.

O ambiente glaciomarinho proximal corresponde, conforme Einsele (1992), a uma área marinha rasa altamente influenciada por águas do degelo de geleiras, carregada de detritos glaciclásticos. Isto implica que, toda sedimentação glaciomarinha de fato corresponde a depósitos continentais que foram reciclados e ressedimentados em ambiente marinho.

\section{DIAMANTES E SUAS POSSÍVEIS RELACCÕES} COM A FORMAÇÃO JEQUITAÍ A maioria dos trabalhos sobre o diamante da região associou sua fonte aos glaciolitos da Formação Jequitaí, desde que Derby (1878) relatou: “... Em um d'estes logares, no arraial de Jequitahy, perto da barra do rio das Velhas, o rio 
Jequitahy é margeado por um conglomerado que tem fornecido os seixos e provavelmente os diamantes aos depósitos mais modernos do leito do rio onde actualmente se encontram...". Outros numerosos estudos foram voltados especificamente para a localização, tipologia e/ou origem desses depósitos diamantíferos (eg., Moraes 1927, Paiva Filho \& Ponçano 1972, Costa et al. 1997, Penha 2001, Penha et al. 2005), incluindo-se o primeiro autor e equipe (eg., Chaves 1997, Chaves et al. 1994, 1998a, 1998b, Karfunkel \& Chaves 1995, Bottino 2000, Chaves \& Bottino 2000, Chaves \& Benitez 2006, Chaves \& Andrade 2009). Destacam-se ainda os trabalhos de Tompkins \& Gonzaga (1989) e Gonzaga \& Tompkins (1991), os quais enfatizaram a possível associação entre diamantes e depósitos glaciogênicos não só em Jequitaí como também em outros locais do Cráton do São Francisco e zonas marginais.

Relacionando-se a distribuição espacial da Formação Jequitaí ao conhecimento geológico anteriormente referido, certas constatações devem ser realçadas. As duas principais áreas diamantíferas de Jequitaí encontram-se numa faixa oeste-leste que inicia na própria cidade e alcança a localidade de Lavrinha, a cerca de $8 \mathrm{~km}$ da mesma. A outra área coincide com o leito e terraços aluvionares do Rio Jequitaí, desde um pouco a montante da cidade dispersando-se progressivamente até cerca de $5 \mathrm{~km}$ rio abaixo, nas proximidades da ponte sobre a BR-365. Ambas as faixas mencionadas coincidem, notavelmente, com a exposição dos depósitos da Formação Jequitaí (Figs. 2 e 6A). Entretanto, essa unidade se distribui por uma região muito mais ampla (conforme descrições no capítulo anterior), onde não foi levantada nenhuma localidade que tenha fornecido diamantes (Chaves \& Benitez 2006). Ressalte-se ainda o caráter alóctone dos cascalhos mineralizados (Fig. 6B).

De maneira distinta, particularmente na extremidade norte da Serra do Cabral (imediações de Fran- cisco Dumont), os estudos efetuados na região pelo autor e equipe, levaram à proposição de uma hipótese diferente. Descobriu-se no topo serrano afloramentos relictos de conglomerados fluviais, relacionados à Formação Abaeté (Chaves et al. 1994, 1998a,b, Karfunkel \& Chaves 1995). Os estudos de paleocorrentes sobre tais conglomerados mostraram uma área-fonte a oeste, onde se situa a Serra do Espinhaço. Admite-se que a serra foi soerguida no Mesozóico, como uma resposta epirogenética à separação continental da América do Sul com a África (King 1956), quando só então os metaconglomerados diamantíferos da Formação Sopa-Brumadinho (Supergrupo Espinhaço) teriam sido exumados. Estes últimos, assim, poderiam contribuir para as fontes do diamante da Serra do Cabral. Chaves (1997) demonstrou ainda a semelhança mineralógica entre as populações de diamantes dessas duas regiões.

Conglomerados idênticos também ocorrem capeando a borda sul da Serra da Água Fria, ao sul de Jequitaí (Fig. 7), e poderiam (seguindo o mesmo princípio da Serra do Cabral) conter diamantes que teriam sido transportados no Cenozóico para os atuais sítios minerados nos arredores da cidade. No entanto, duas novas considerações recentemente se somaram no sentido de melhor entendimento da questão. Tendo por base os estudos que relacionaram a possível presença de diamantes na Formação Abaeté, os conglomerados da Serra da Água Fria foram pesquisados pelo consórcio COMIG-GEOEXPLORE (Costa et al. 1997), não tendo recuperado nenhum diamante em tal rocha (Penha 2001, comunic. verbal). Corroborando com essa informação, o mapeamento da Folha Jequitaí também não constatou qualquer localidade de ocorrência de diamantes em aluviões recentes associados àquela borda serrana (Chaves \& Benitez 2006).

Existe uma nítida diminuição no porte e número de garimpos aluvionares de diamantes na direção a
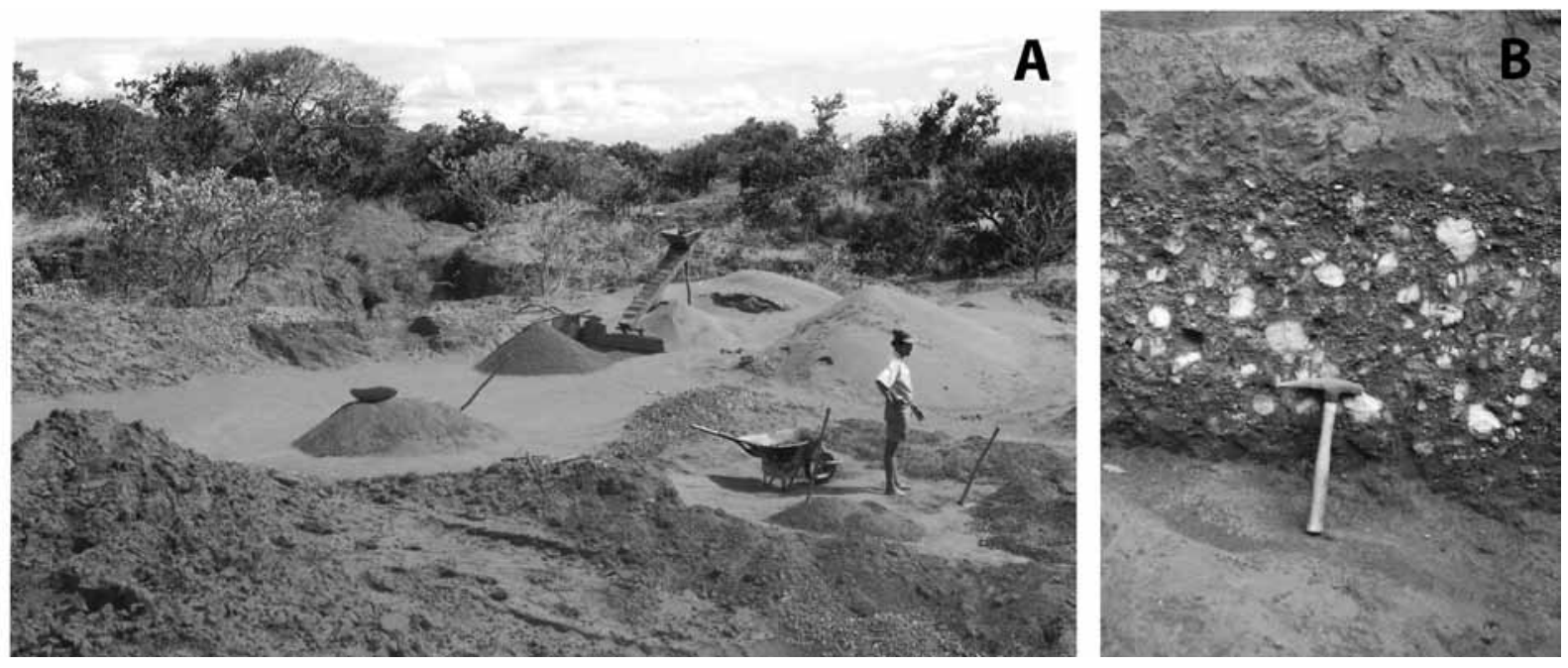

Figura 6 - (A) Aspecto geral da garimpagem de diamantes a leste de Jequitaí (Lavra da Coruja); (B) destacando ainda o cascalho coluvionar com $50-60 \mathrm{~cm}$ de espessura cobrindo o bedrock ai formado por metadiamictitos muito alterados. 


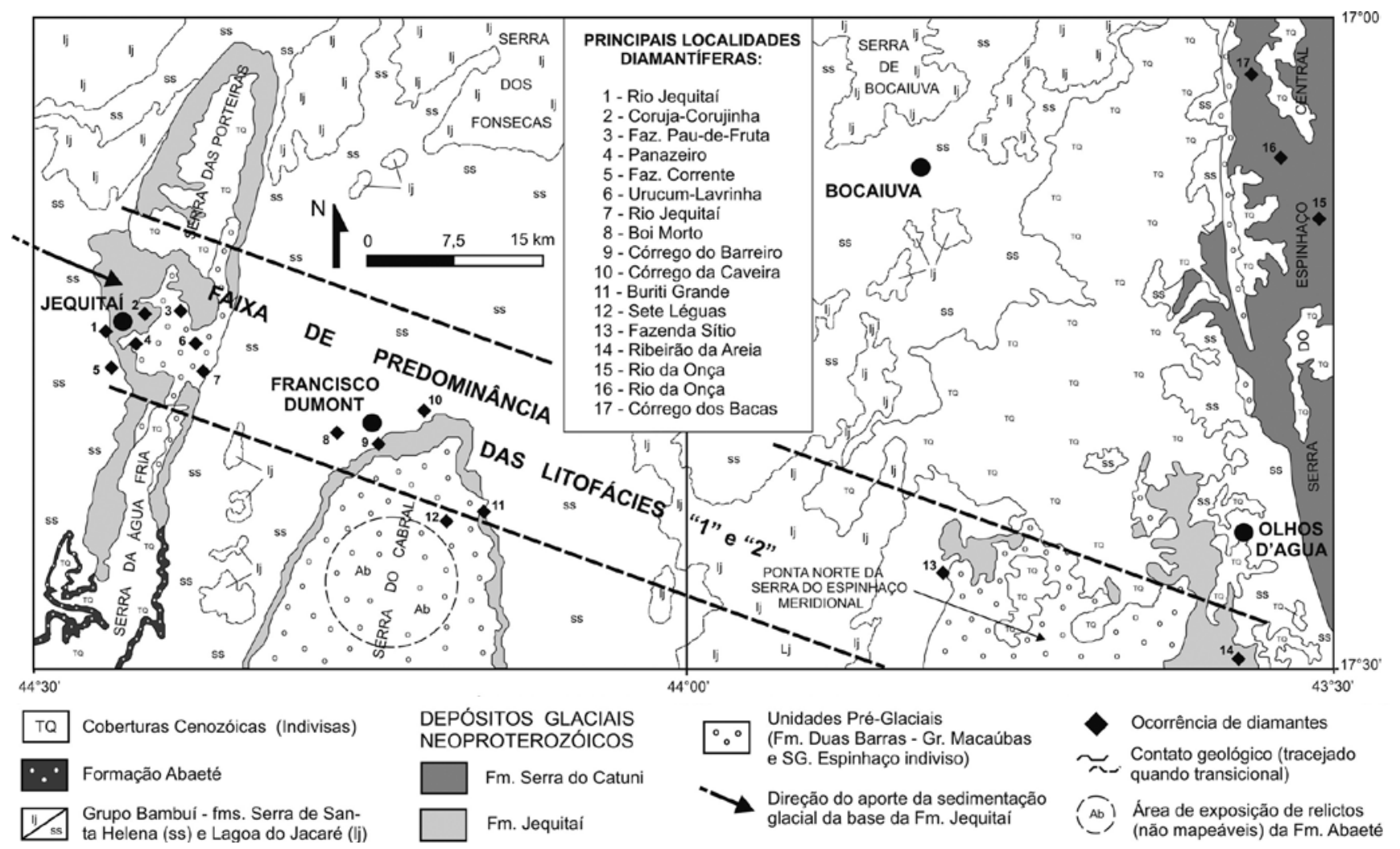

Figura 7 - Geologia simplificada das folhas Jequitai e Bocaiuva, ressaltando-se a estreita associação entre os depósitos diamantíferos da Formação Jequitai com a área de predominância das litofácies L1 e L2 (modificada de Chaves \& Benitez 2006, Chaves \& Andrade 2009).

sudeste desde Jequitaí até Olhos d'Água (Fig. 7), nitidamente indicando também que sua(s) rocha(s) fonte(s) está(ão) se tornando mais escassa(s) e/ou mais pobre(s) no mineral. Assim, na Folha Bocaiuva, os sedimentos diamantíferos possivelmente relacionados à Formação Jequitaí tornam-se muito menos frequentes, além de inexpressivos em termos econômicos, e não existe qualquer suspeita de depósitos derivados dos conglomerados cretácicos. Aluviões diamantíferos voltam a ocorrer na borda leste dessa folha, fora do corredor Jequitaí-Olhos d'Água, na região do Rio da Onça. Entretanto, como a unidade glaciogência aí presente é alóctone (Formação Serra do Catuni), transportada de leste para oeste em direção ao cráton, a questão da origem de tais diamantes deve ser procurada na faixa da Serra do Espinhaço a leste (Folha Itacambira).

CONCLUSÃO Os estudos paleoambientais efetuados na Formação Jequitaí, bem como as reinterpretações propostas, demonstram mudanças importantes na caracterização dos ambientes internos de sedimentação presentes nessa unidade e, consequentemente, num significativo avanço para o entendimento da origem dos depósitos diamantíferos regionais. Além disso, a revisão geral da questão ora apresentada indica a complexidade e, por conseguinte, o interesse científico historicamente envolvido na relação da estratigrafia com as mineralizações de diamantes distribuídos na faixa entre Jequitaí e Olhos d'Água.
A primeira constatação é de que sedimentos diamantíferos cenozóicos aparecem preferencialmente em sobreposição, ou nas imediações de ocorrências dos metadiamictitos da seção basal da Formação Jequitaí e que, ainda, somente as rochas da Litofácies L1 possuem tal atributo, justamente as encontradas no Rio Jequitaí e na faixa a leste da cidade. Baseado nesses argumentos, aponta-se para uma associação íntima entre a presença de diamantes com sedimentos glaciomarinhos proximais, depósitos estes formados em processos gravitacionais pelo degelo de base de geleiras. Deve ser ressaltada a pequena espessura $(<40 \mathrm{~m})$ de tais depósitos em relação à unidade inteira $(>200 \mathrm{~m})$. Entretanto, acredita-se que mesmo nos locais considerados "ricos" em diamantes os teores sejam ínfimos; suposição esta corroborada na integração dos dados geoeconômicos locais disponíveis (Chaves \& Benitez 2006).

Assim, embora tais depósitos possam ser inexpressivos em termos econômicos, as suas implicações em termos estratigráficos, sedimentológicos e tectônicos são significantes, e estimularam os inúmeros estudos a respeito. Em suma, acredita-se que os argumentos aqui levantados possam permitir um melhor entendimento da Formação Jequitaí, conforme as constatações de que:

(i) Nem todos os glaciolitos dessa formação são diamantíferos; somente aqueles associados à Litofácies L1 possuem sedimentos cenozóicos mineralizados em suas proximidades.

(ii) A Litofácies L1 não pode ser exclusivamen- 
te a fonte dos diamantes dos depósitos recentes, pois diversos deles ocorrem em zonas onde, pela estruturação local, a Formação Jequitaí não poderia estar presente.

(iii) Esses depósitos são preferencialmente mineralizados, e logo lavrados com maior frequência, em locais onde também ocorre aporte de material proveniente dos conglomerados cretácicos (quando diamantíferos);

Os processos de reconcentração do mineral, certamente foram favorecidos por meio de uma importante fase de reativação neotectônica local, ainda mal estudada, conforme já observada nos arredores de Jequitaí por Chaves \& Bottino (2000) e Penha et al.
(2005). De tal maneira, essa multiplicidade de depósitos fonte secundários pode ser fator determinante para uma distribuição aparentemente aleatória da mineralização, e o principal fator responsável pela quase incontrolabilidade prospectiva da mesma.

Agradecimentos Os autores agradecem à CPRM Serviço Geológico do Brasil, pelos auxílios concedidos à execução do mapeamento geológico das folhas Jequitaí e Bocaiuva, bem como ao coordenador-geral desses projetos no âmbito da UFMG, Prof. Dr. Antônio Carlos Pedrosa Soares.

\section{Referências}

Babinski M. 2005. A idade do Supergrupo São Francisco: revisão e implicações nas glaciações neoproterozóicas. In: SBG, Simpósio sobre o Cráton do São Francisco, 3, Salvador, Short Papers, p.135-138.

Babinski M. \& Kaufman A.J. 2003. First direct dating of a Neoproterozoic post-glacial cape carbonate. In: South American Symposium on Isotope Geology, 4, Salvador, Short Papers, p.321-323.

Bottino E.C.C. 2000. Tipologia, aspectos mineralógicos e econômicos dos depósitos diamantíferos das regiões de Jequitai e Francisco Dumont, MG. Dissertação de Mestrado, IG, Universidade Federal de Minas Gerais, 195 p.

Branner J.C. 1919. Outlines of the geology of Brazil to accompany the geological map of Brazil. Geological Society of America Bulletin, 30:189-338.

Chang H.K., Miranda F.P., Magalhães L., Alkmim F.F. 1988. Considerações sobre a evolução tectônica da Bacia do São Francisco. In: SBG, Congresso Brasileiro de Geologia, 35, Belém, Anais, p.2076-2090.

Chaves M.L.S.C. 1997. Geologia e mineralogia do diamante da Serra do Espinhaço em Minas Gerais. Tese de Doutoramento, IGc, Universidade de São Paulo, 289 p.

Chaves M.L.S.C. \& Bottino E.C.C. 2000. Evolução geológica multifásica dos depósitos diamantíferos da região de Jequitaí, Minas Gerais. Geociências, 19:197-208.

Chaves M.L.S.C. \& Benitez L. 2006. Folha Jequitai 1:100.000 Relatório Final. Programa Geologia do Brasil, Convênio CPRM-IGC/UFMG, Brasília, 45 p.

Chaves M.L.S.C. \& Andrade K.W. 2009. Folha Bocaiúva 1:100.000 Relatório Final. Programa Geologia do Brasil, Convênio CPRM-IGC/UFMG, Brasília, 73 p.

Chaves M.L.S.C., Karfunkel J., Pena J.L.M. 1994. Depósitos coluviais diamantíferos da região de Jequitaí - Francisco Dumont, Minas Gerais. In: SBG, Congresso Brasileiro de Geologia, 38, Balneário Camboriú, Anais, p.189-190.

Chaves M.L.S.C., Karfunkel, J., Castro E.C. 1998a. Novas considerações sobre a origem do diamante de Jequitaí (MG). In: SBG, Congresso Brasileiro de Geologia, 40, Belo Horizonte, Anais, p. 288.

Chaves M.L.S.C., Karfunkel J., Svisero D.P. 1998b. Lower cretaceous conglomerates in the Southern São Francisco basin, Minas Gerais: a model for the redistribution of ancient diamonds to Cenozoic colluvial-alluvial deposits. Anais da Academia Brasileira de Ciências, 70:477-490.
Costa K.V., Penha U.C., Araújo M.C. 1997. Conglomerado cretáceo com potencial diamantífero na Serra da Água Fria (MG). In: SBG, Simpósio de Geologia de Minas Gerais, 9, Belo Horizonte, Anais, p.132-133.

Cukrov N. 1999. A glaciação neoproterozóica na porção sul do Cráton São Francisco e suas litofácies nas regiões de Jequitaí-MG e Cristalina-GO. Dissertação de Mestrado, Instituto de Geociências, Universidade de Brasília, 104 p.

Cukrov N., Alvarenga C.J.S., Uhlein A. 2005. Litofácies da glaciação neoproterozóica nas porções sul do Cráton do São Francisco: exemplos de Jequitaí (MG) e Cristalina (GO). Revista Brasileira de Geociências, 35:69-76.

Dardenne M.A., Faria A., Magalhães L.F., Soares L.A. 1978. O tilito da base do Grupo Bambuí na borda ocidental do Cráton São Francisco. In: SBG, Núcleo Centro-Oeste, Boletim Informativo 7-8:85-97.

Derby O.A. 1878. Contribuição para o estudo da geologia do vale do São Francisco. Archivos do Museu Nacional, 4:87119.

Derby O.A. 1879. Observações sobre algumas rochas diamantíferas da Província de Minas Gerais. Archivos do Museu Nacional, 4:121-132.

Dussin T.M. 1994. Associations plutono-volcaniques de l'Espinhaço Méridional: un exemple d'évolution de la croûte protérozö̈que. These Docteurement, Université d'Orleans, $177 \mathrm{p}$.

Einsele G. 1992. Sedimentary Basins Evolution, Facies and Sediment Burdget. Berlin, Springer-Verlag, $421 \mathrm{p}$.

Gonzaga G.M. \& Tompkins L. 1991. Geologia do Diamante. In: Schobbenhaus C., Queiroz E.T., Coelho C.E.S. (eds.) Principais Depósitos Minerais do Brasil. Vol. IV, parte A, Núcleo de Edições Técnicas - CPRM. Brasília, DNPMCVRD, p. 53-116.

Gravenor C.P. \& Monteiro R.L.B.P. 1983. Ice-thrust features and a possible intertillite pavement in the Proterozoic Macaúbas Group, Jequitaí area, Minas Gerais, Brazil. Journal of Geology, 91:113-116.

Guimarães J.T. 1996. A Formação Bebedouro no Estado da Bahia: faciologia, estratigrafia e ambientes de sedimentação. Dissertação de Mestrado, Instituto de Geociências, Universidade Federal da Bahia, 155 p.

Hercos C.M. \& Martins-Neto M.A. 1997. Considerações sobre os supergrupos São Francisco e Espinhaço ao longo da borda oeste da Serra da Água Fria (MG). In: SBG, Simpó- 
sio de Geologia de Minas Gerais, 9, Anais, p.19-21.

Hettich M. 1977. A glaciação proterozóica no centro-norte de Minas Gerais. Revista Brasileira de Geociências, 7:87-101.

Hettich M. \& Karfunkel J. 1978. Um esker, um varvito e seixos estriados no Grupo Macaúbas - norte de Minas Gerais. Revista Escola de Minas, 34:5-8.

Isotta C.A.L., Rocha-Campos A.C., Yoshida R. 1969. Striated pavement of the Upper Pre-Cambrian glaciation in Brazil. Nature, 222:466-468.

Karfunkel B. \& Karfunkel J. 1976. Estudos petro-faciológicos do Grupo Macaúbas na porção mediana da Serra do Espinhaço - MG. In: SBG, Congresso Brasileiro de Geologia, 29, Belo Horizonte, Anais, p.179-188.

Karfunkel J. \& Hoppe A. 1988. Late Proterozoic glaciation in central Eastern Brazil: synhesis and model. Palaeogeography, Palaeoclimatology, Palaeoecology, 65:1-21.

Karfunkel J. \& Chaves M.L.S.C. 1995. Conglomerados cretácicos da Serra do Cabral, Minas Gerais: um modelo para a redistribuição coluvio-aluvionar dos diamantes do Médio São Francisco. Geociências, 14:59-72.

King L. 1956. A geomorfologia do Brasil Oriental. Revista Brasileira de Geografia, 18:147-266

Machado N., Schrank A., Abreu F.R., Knauer L.G., AlmeidaAbreu P.A. 1989. Resultados preliminares da geocronologia U-Pb na Serra do Espinhaço Meridional. In: SBG, Simpósio de Geologia de Minas Gerais, 5, Diamantina, Anais, p.171-174.

Martins M.S. 2006. Geologia dos diamantes e carbonados da bacia do Rio Macaúbas (MG). Tese de Doutoramento, Instituto de Geociências, Universidade Federal de Minas Gerais, 231 p.

Martins-Neto M.A. 1998. O Supergrupo Espinhaço em Minas Gerais: registro de uma bacia rifte-sag do Paleo/Mesoproterozóico. Revista Brasileira de Geociências, 28:151-168.

Martins-Neto M.A. \& Hercos C.M. 2002. Sedimentation and tectonic setting of Early Neoproterozoic glacial deposits in south-eastern Brazil. In: Altermann W.A. \& Corcoran P.L. (eds.) Precambrian sedimentary environments: a modern approach to ancient depositional systems. New York, Internat. Assoc. of Sediment. Publ., Wiley-Blackwell, p. 383-403

Martins-Neto M.A., Castro P.T.A., Hercos C.M. 1997. O Supergrupo São Francisco (Neoproterozóico) no Cráton do São Francisco em Minas Gerais. In: SBG, Simpósio de Geologia de Minas Gerais, Diamantina, 9, Anais, p. 2224.

Martins-Neto M.A., Gomes N.S., Hercos C.M., Reis L.A. 1999. Fácies glaciocontinentais (outwash plain) na megassequência Macaúbas (Serra da Água Fria, MG) e seu contexto tectônico. Revista Brasileira de Geociências, 29:179-188.

Menezes Filho N.R., Mattos G.M.M., Ferrari P.G. 1977. Projeto Três Marias. B.Horizonte, Conv.DNPM/CPRM, 550 p.

Moraes L.J. 1927. Algumas jazidas de diamante no norte de Minas Gerais. Boletim do Serviço Geológico e Mineralógico do Brasil, 24:49-65.

Moraes L.J. 1932. Área ocupada pela Formação Macahúbas no norte de Minas Gerais. Anais da Academia Brasileira de Ciências, 4:111-114.

Moraes L.J. \& Guimarães D. 1930. Geologia da região dia- mantífera do norte de Minas Gerais. Anais da Academia Brasileira de Ciências, 2:153-186.

Noce C.M., Pedrosa-Soares A.C., Grossi-Sad J.H., Baars F.J., Guimarães M.L.V., Mourão M.A.A., Oliveira M.J.R., Roque N.C. 1997. Nova divisão estratigráfica regional do Grupo Macaúbas na Faixa Araçuaí; registro de uma bacia neoproterozóica. In: SBG, Simpósio de Geologia de Minas Gerais, 9, Belo Horizonte, Anais, p. 29-30.

Oliveira A.I. \& Leonardos O.H. 1943. Geologia do Brasil. Ministério da Agricultura, Rio de Janeiro, 613 p.

Paiva Filho A. \& Ponçano W.L. 1972. Mapa geológico preliminar da região de Jequitaí, Estado de Minas Gerais. In: SBG, Cong. Bras. de Geologia, 26, Anais, p. 95-102.

Pedrosa-Soares A.C., Cordani A.G., Nutman A. 2000. Constraining the age of Neoproterozoic glaciation in eastern Brazil: first U-Pb (SHRIMP) data of detrital zircons. Revista Brasileira de Geociências, 30:58-61.

Penha U.C. 2001. Geologia dos conglomerados cretáceos da Serra da Água Fria e dos depósitos diamantíferos de Jequitaí. Tese de Doutoramento, Instituto de Geociências e Ciências Exatas, Universidade Estadual Paulista, 148 p.

Penha U.C., Karfunkel J., Angeli N. 2005. Diamondiferous deposits in the Jequitaí area (Minas Gerais, Brazil): a consequence of neotectonic processes. N. Jb. Geol. Paläont. Abh., 236:207-224.

Pflug R. \& Schöll W.U. 1975. Proterozoic glaciations in eastern Brazil: a review. Geologisch Rundschau, 64:287-299.

Sgarbi G.N.C. 2000. The Cretaceous Sanfranciscan basin, Eastern Plateau of Brazil. Revista Brasileira de Geociências, 30:450-452.

Souza A.A. 1985. Projeto Mapas Metalogenéticos e de Previsão de Recursos Minerais, Folha SE.23-X-C Pirapora. Belo Horizonte, Convênio DNPM/CPRM, 50 p.

Tompkins L.A. \& Gonzaga G.M. 1989. Diamonds in Brazil and a proposed model for the origin and distribution of diamond in the Coromandel region, Minas Gerais, Brazil. Economic Geology, 84:591-602.

Uhlein A., Trompette R.R., Alvarenga C.J.S. 1999. Neoproterozoic glacial and gravitational sedimentation on a continental rifted margin: the Jequitaí-Macaúbas sequence (Minas Gerais, Brazil). Journal of South American Earth Sciences, 12:435-451.

Uhlein A., Alvarenga C.J.S., Trompette R., Dupont H.S.J.B., Egydio-Silva M., Cukrov N., Lima O.N.B. 2004. Glaciação neoproterozóica sobre o Cráton do São Francisco e faixas dobradas adjacentes. In: Mantesso-Neto V., Batorelli A., Carneiro C.D.RBrito-Neves, B.B. (orgs.) Geologia do Continente Sul-Americano: evolução da obra de Fernando Flávio Marques de Almeida. São Paulo, p.539-553.

Uhlein A., Trompette R.R., Egydio-Silva M., Vauchez A. 2007. A glaciação Sturtiana ( $750 \mathrm{Ma})$, a estratigrafia do rifte Macaúbas-Santo Onofre e a estratigrafia do Grupo Macaúbas, Faixa Araçuaí. Geonomos, 15:45-60.

Viveiros J.F.M. \& Walde D. 1976. Geologia da Serra do Cabral, Minas Gerais, Brasil. Münsterische Forschungshefte Geologie und Paläontologie, 38-39:15-27.

Manuscrito ID16872

Submetido em 19 de fevereiro de 2010 Aceito em 22 de novembro de 2010 